\title{
Las relaciones entre la Corona y la aristocracia española durante el reinado de Carlos IV: el caso del XIII duque del Infantado (1791-1808)
}

\author{
Relationships between the Crown and the Spanish Aristocracy \\ during the Reign of Charles IV: the Case of the \\ Duke of Infantado (1791-1808)
}

\author{
María del Mar Alarcón Alarcón \\ Universidad de Alicante
}

Recibido: 11-I-2012

Aceptado: 12-III-2012

\section{Resumen}

En este artículo se estudia el papel político que el duque del Infantado jugó entre 1804 y marzo de 1808 como miembro de la facción cortesana llamada partido fernandino. Se parte del supuesto de que la conducta política de este aristócrata respondió en última instancia al doble intento de contener el desarrollo de las medidas de corte reformista impulsadas por la Corona y de acabar con la figura del Generalísimo-Almirante, que encarnó Manuel Godoy. Con la defensa de un modelo de monarquía moderada, Infantado pretendió evitar cualquier menoscabo al poder social e intereses de su Casa. Esta actitud hostil a la orientación política que Carlos IV imprimió a la monarquía fue compartida por una parte de la antigua aristocracia española, como se desprende del expediente judicial incoado tras la conspiración de El Escorial o del estudio de la composición de los apoyos sociales que recibió Fernando VII al llegar al trono. Especial atención se presta a la actuación de Infantado en la conspiración de El Escorial y en los acontecimientos inmediatamente posteriores al motín de Aranjuez, manifestaciones inequívocas de la grave crisis política en que se hallaba sumida la monarquía española a la altura de 1807 y 1808 .

Palabras clave: Duque del Infantado, Antiguo Régimen, Absolutismo, Monarquía hispánica, Aristocracia, Partido fernandino.

\section{Abstract}

This article examines the political role played by the Duke of Infantado (Madrid, 17681841) from 1804 to March of 1808 as member of the court faction called Ferdinand's party. The main argument is that this aristocrat followed a double objective until the 
crisis of the Old Regime. On the one hand, he wanted to contain the reformist measures taken by the Crown. On the other hand, Infantado tried the fall of the new figure of the Generalissimo and Grand Admiral: Emmanuel Godoy, whose creation had contribued to the reinforcement of the absolute monarchy. In defending the idea of moderate and traditional monarchy, he pursued not only limiting the increasingly "despotic power" of the monarchy, but also safeguarding the social power and interests of his House. This hostile attitude against the political measures of Charles IV was taken by the great majority of the ancient aristocratic families. We will pay special attention to his role in the conspiracy of the Escurial, and to his conduct as member of the first government of Ferdinand VII.

Keywords: Duke of Infantado, Old Regime, Absolutism, Spanish Monarchy, Aristocracy, Ferdinand's party.

\section{Introducción}

La profunda crisis política abierta en la monarquía hispánica durante el reinado de Carlos IV supuso uno de los antecedentes inmediatos de la descomposición del Antiguo Régimen, un proceso histórico que en lo fundamental se desenvolvería durante el reinado de su sucesor ${ }^{1}$. En el panorama historiográfico se advierten carencias importantes en lo que respecta al conocimiento de las posiciones políticas que las élites sociales dominantes -aristocracia y jerarquía eclesiástica- adoptaron en ese contexto de crisis previo al estallido de la revolución liberal. Dicho vacío se acusa aún más cuando se pregunta por las relaciones que la antigua aristocracia en particular mantuvo con la Corona, y por la incidencia que la política de reformas impulsada entre 1798 y marzo de 1808 ejerció sobre la evolución de las mismas.

Múltiples estudios han venido insistiendo en la estrecha vinculación que significados miembros de la aristocracia mantuvieron con distintas facciones cortesanas disconformes con los cambios introducidos en el sistema de gobierno de la monarquía durante la segunda mitad del siglo XVIII². Entre ellas merece especial atención, por la extraordinaria capacidad de actuación y de presión política que demostró entre 1806 y 1807, el partido fernandino ${ }^{3}$. Este

1. Acerca el debate en torno a los límites temporales del Antiguo Régimen en la monarquía española, véase: LA PARRA LÓPEZ, Emilio, "El legado político del Antiguo Régimen", en LLOPIS AGELÁN (coord.), El legado económico del Antiguo Régimen en España, Barcelona Crítica, 2004, pp. 77-96.

2. Es el caso del partido arandista. Véase: OLAECHEA, Rafael y FERRER BENIMELI, José Antonio, El conde de Aranda (mito y realidad de un político aragonés), vol. II, Zaragoza, Librería General, 1978. Acerca del llamado "círculo jansenista", consúltese el clásico trabajo de: DEMERSON, Paula, María Francisca Sales de Portocarrero: condesa del Montijo, Madrid, Editora Nacional, 1975.

3. La polisémica voz partido (del latín pars-partis, parte), de uso común en la segunda mitad del siglo XVIII, indicaba "división". Cuando se aplicaba al terreno de la alta política, 
grupo, formado en torno al príncipe de Asturias hacia 1804, cifró sus objetivos en forzar la caída de Manuel Godoy -cuyo ejercicio del poder juzgó tiránico y despótico- y en propiciar la llegada al trono del futuro Fernando VII, unos propósitos que se vieron consumados inmediatamente después del motín de Aranjuez (17-19 de marzo de 1808).

Con el fin de contribuir al conocimiento de los problemas planteados, en estas páginas trataremos de reconstruir la primera etapa diferenciada en la trayectoria política del XIII duque del Infantado, Pedro Alcántara de Toledo y Salm-Salm (Madrid, 1768-1841), destacado miembro del partido fernandino, lo que significa que nos moveremos en un horizonte cronológico que situamos entre 1804 y marzo de $1808^{4}$. No obstante, para abundar en la comprensión del objeto de estudio será preciso retrotraerse en el tiempo hasta 1791, fecha en la que este personaje sucedió a su predecesor en la cabeza del ducado.

Se parte de la premisa de que la conducta política del aristócrata, desplegada a la sombra del poder real hasta la subida al trono de Fernando VII, obedeció en última instancia al intento de mantener intactos el poder social, consideración e intereses de su Casa, que juzgó amenazados por la política de reformas de la Corona y sobre todo por la creación de la figura del generalísimo permanente de los ejércitos (Real Decreto de 12 de noviembre de 1801). Especial atención se prestará a la participación de Infantado en la conspiración de El Escorial (octubre de 1807) y en los acontecimientos políticos que se derivaron del motín de Aranjuez, los cuales acabaron favoreciendo el ascenso del duque a las más altas instancias de poder de la monarquía.

refería por lo común la existencia de disensiones en la corte motivadas por la actuación de distintos grupos de presión o influencia. Éstos, por lo general, se agrupaban en torno a un individuo de significada condición social o política, que figuraba como su cabeza visible. Sobre el término partido, ver: FERNÁNDEZ SARASOLA, Ignacio, Los partidos políticos en el pensamiento español: de la Ilustración a nuestros días, Madrid, Marcial Pons, 2009, p. 25. Para el estudio de la formación, composición y actuaciones del partido fernandino, son de obligada referencia los trabajos del profesor Emilio LA PARRA: "De la disputa cortesana a la crisis de la monarquía. Godoyistas y fernandinos en 1806-1807", Cuadernos de Historia Moderna. Anejos, VI (2007), pp. 255-267; "Los hombres de Fernando VII en 1808", en ALBEROLA, Armando, y LARRIBA, Elisabel (eds.), Las élites y la "revolución de España". Estudios en homenaje al profesor Gérard Dufour, Alicante, Universidad de Alicante, 2010, pp. 127-152.

4. El XIII duque del Infantado, grande de España de primera clase, fue entre 1791 y 1841 titular de una de las casas aristocráticas de mayor antigüedad y que mayor poder e influencia social tuvieron en la monarquía española. Este aristócrata fue alto cargo del Estado absoluto en tiempos de Fernando VII (1808-1833) y miembro de la jerarquía castrense. Para una aproximación a su figura, consúltese: MOXÓ, Salvador de: "El duque del Infantado don Pedro Alcántara de Toledo y Salm y Salm. Un personaje de la nobleza en la transición del Antiguo Régimen a la época contemporánea", Hispania: Revista española de Historia, $\mathrm{n}^{\circ} 137$ (1977), pp. 569-599; CARRASCO MARTÍNEZ, Adolfo, El poder de la sangre. Los duques del Infantado, 1601-1841, Madrid, 2010, pp.118-162. 
En opinión de quien esto escribe, el caso de este personaje constituye una muestra representativa del posicionamiento político que adoptó la mayor parte de la aristocracia frente a la orientación dada a la monarquía en tiempos de Carlos IV, un supuesto cuya verificación nos obligará a prestar atención al comportamiento político que siguieron otros aristócratas de su tiempo.

Para alcanzar los objetivos trazados, se ha recurrido a la consulta de diversas fuentes documentales que serán analizadas desde una perspectiva política y social. Entre ellas, cabe destacar aquí los expedientes judiciales, la correspondencia privada y diplomática, diversos escritos suscritos por el propio personaje histórico y, por último, las memorias de los contemporáneos.

\section{Las relaciones entre la Casa del Infantado y el poder real: 1791-1804 Dos trayectorias en paralelo: Manuel Godoy e Infantado}

Grosso modo, podría afirmarse que durante la mayor parte de la Edad Moderna la dignidad de grande de España estuvo reservada a la aristocracia, grupo social hegemónico que estaba muy lejos de identificarse con los estratos inferiores del estamento nobiliario 5 . Pero a la altura de la segunda mitad del siglo XVIII el ascenso en la jerarquizada sociedad del Antiguo Régimen no sólo pendía del nacimiento, sino también de la voluntad soberana de aquel que se situaba en su vértice: el rey. El desplazamiento de la antigua aristocracia de los más altos cargos de gobierno de la monarquía, observable durante el reinado de Carlos IV, se explicaría sobre todo por los intentos de reducir su influencia política y afianzar el ámbito jurisdiccional de la Corona ${ }^{6}$. A estos móviles habría que añadir el interés de la dinastía Borbón por continuar potenciando la política patrimonialista y la vía gubernativa, objetivos que habían sido perseguidos a lo largo de la primera mitad del siglo XVIII y que suscitaron los recelos de la aristocracia ${ }^{7}$.

5. El término nobleza en modo alguno es sinónimo de aristocracia. No es ocioso recordar que el estamento nobiliario presentaba un elevado grado de jerarquización interna, lo que quiere decir que no todos los estratos nobiliarios gozaban de igual rango y consideración social. En el seno mismo de la grandeza de España se distinguían tres calidades, a saber: la grandeza de primera clase, de segunda y de tercera, cada una de las cuales poseía unos privilegios honoríficos exclusivos que adquirían gran importancia en el ámbito cortesano, y que eran símbolo y manifestación de poder social. En la heterogénea composición del estamento nobiliario ha insistido el profesor Antonio DOMÍNGUEZ ORTIZ en Las clases privilegiadas en el Antiguo Régimen, Madrid, Istmo, 1973, esp. pp. 49-187.

6. Cfr. SÁNCHEZ-BLANCO, Francisco, La Ilustración goyesca. La cultura en España durante el reinado de Carlos IV (1788-1808), Madrid, CEPC., 2007, pp. 99 y 100.

7. La postergación de los órganos polisinodiales de la monarquía suscitó la oposición de la mayor parte de la aristocracia española, que a la sazón contaba con una importante presencia en los mismos. Como es sabido, en este enfrentamiento se significó, durante los reinados de Carlos III y Carlos IV, el X conde de Aranda. Ver: CORONAS GONZÁLEZ, 
Por otra parte, la positiva valoración del mérito y de la capacidad del súbdito-servidor del rey, con independencia de su condición aristocrática o no, estaba avalada por las nuevas ideas del siglo. Sirva como ejemplo el Informe que Jovellanos elevó al rey en 1795, en el que afirmaba: "es una verdad innegable que la virtud y los talentos no están vinculados al nacimiento ni a las clases, y que por lo mismo fuera una grave injusticia cerrar a algunas el paso a los servicios y a los premios". Aún más provocadoras resultaban las palabras que Cadalso vertiera en sus Cartas marruecas: "nobleza hereditaria es la vanidad que yo fundo en que ochocientos años antes de mi nacimiento muriese uno que se llamó como yo me llamo, y fue hombre de provecho, aunque yo sea inútil para todo" ${ }^{8}$.

Carlos III (1759-1788) no llamó al XII titular del Infantado (1729-1790) a participar en la alta política, y por su condición de antiguo grande de España, su ideal de "monarquía moderada" y el poder social que ya acumulaba su casa -en buena medida debido a la posesión de extensos dominios señoriales-, Carlos IV tampoco consideró al XIII duque como un candidato idóneo al que situar en la cumbre del poder ${ }^{9}$. Caso muy distinto fue el de Manuel Godoy, de origen hidalgo. En 1792 recibía por real orden los títulos de grande de España de primera clase y duque de la Alcudia, pasando a formar parte de una nueva aristocracia de cuño real, que fue vista con animadversión por los antiguos linajes. En noviembre de este último año, a la caída de Aranda, la cabeza visible del partido aragonés, Godoy asumía la primera Secretaría de Estado y del Despacho. Así pues, en el momento en el que nuestro personaje comenzaba a asumir el control de sus estados señoriales, Godoy, gracias al imprescindible favor del rey, iniciaba su meteórica carrera hacia las más elevadas esferas del Estado ${ }^{10}$.

Santos M., Ilustración y derecho. Los fiscales del Consejo de Castilla en el siglo XVIII, Madrid, 1992, p. 238. FERRER BENIMELI, José A., "El X Conde de Aranda y Aragón", en CASAUS BALLESTER, $\mathrm{M}^{a}$ José (Ed.), El Condado de Aranda y la nobleza española en el Antiguo Régimen, Zaragoza, Institución Fernando el Católico, 2009, pp. 317-318. Sobre la potenciación de la política patrimonialista de la Corona y de la vía gubernativa, es de obligada referencia el trabajo de: FERNÁNDEZ ALBALADEJO, Pablo, Fragmentos de monarquía: trabajos de historia política, Madrid, Alianza, 1992, esp. pp. 433-456.

8. JOVELLANOS, Melchor Gaspar de, Informe de la Sociedad Económica de Madrid al real y supremo Consejo de Castilla en el expediente de la ley agraria, Imprenta de Sancha, 1795; CADALSO, Cartas Marruecas. Noches lúgubres, Barcelona, Crítica, 2000, p. 55.

9. El punto cuarto del presente trabajo se dedica precisamente a desentrañar el ideal de monarquía que Infantado defendió entre 1804 y 1808.

10. Una real cédula de 27 de enero de 1791 dispensaba la minoría de edad a Pedro Alcántara de Toledo, de veintitrés años, capacitándolo "para regir, gobernar y administrar vuestra Casa, Estados y mayorazgos sin la asistencia de curador ni tutor (...) como si fuerais de edad cumplida de 25 años (...)", en Sección Nobleza del Archivo Histórico Nacional (SNAHN), Osuna, leg. 1769, doc.3. 
Infantado fue llamado por real orden a participar en la Guerra contra Portugal (1801) en calidad de mariscal de campo. Si al término de este fugaz conflicto un real decreto de 4 octubre convertía a Godoy en Generalísimo, capacitándolo para emprender la ansiada reforma de los ejércitos y de la armada -propósito que también suscitó las suspicacias de la aristocracia-, Infantado era promovido al grado de teniente general, un nombramiento, si bien no exento de importancia, a todas luces inferior si se compara con el que había recibido el príncipe de la Paz, que se convertía de facto en el primer hombre de la monarquía después del rey ${ }^{11}$.

Con la creación de la figura del Generalísimo, en la monarquía española se abría un nuevo panorama político con respecto al de la primera etapa del reinado de Carlos IV, un cambio que, siguiendo al profesor Emilio La Parra, se explica por la concurrencia de dos circunstancias: "una profunda crisis [política] interna en España y el ataque a la monarquía en Francia" ${ }^{2}$. Si hasta ese momento la figura del Secretario de Estado había sido determinante en el diseño de las grandes líneas de actuación política, desde 1801 "la figura del secretario de Estado carece de relevancia y la orientación de la monarquía emana del centro extragubernamental constituido por los reyes y Godoy"13.

\section{La aristocracia frente a la política reformista de la Corona}

Antes de entrar en el estudio del problema que da título a este epígrafe, conviene realizar una serie de anotaciones a fin de comprender el sentido y alcance de la política reformista emprendida por la Corona.

Anotaba Norbert Elias que el Estado moderno, a diferencia del contemporáneo, se encontraba muy lejos de concentrar en la práctica el monopolio del poder, y advertía que el concepto de absolutismo era equívoco y susceptible de

11. Infantado recibe este ascenso el 5 de noviembre de 1802. El expediente militar de Pedro Alcántara de Toledo y Salm-Salm se localiza en: Archivo Militar de Segovia (AMS), Personajes célebres, c(aja) 161, exp. 10.

12. LA PARRA LÓPEZ, Emilio, Manuel Godoy. La aventura del poder, Barcelona, Tusquets, 2005 , p. 97.

13. Ibidem., p. 244. A la hora de explicar estos cambios políticos de orden interno, habría que atender también a la evolución política de Francia, donde desde 1799 una figura militar concentrará cada vez mayor poder personal: Napoleón Bonaparte. Concluye el profesor Emilio La Parra a este respecto que "Face aux attentes concernant l'ordre international suscitées en 1801 par l'importance grandissante de Bonaparte, Charles IV pense qu'il fallait à présent introduire des changements pour adapter sa monarchie à la nouvelle situation sans altérer son essence. Bonaparte offrit précisément le modèle à suivre », Cfr. « Méfiance entre les alliés. Les relations Napoléon-Godoy (1801-1807) », Annales historiques de la Révolution Française, no 336 (avril-juin 2004), p. 26. 
provocar confusiones ${ }^{14}$. En estas páginas, con el controvertido concepto de absolutismo se refiere, más que una forma de gobierno, una "tendencia a ejercer el poder soberano de modo no compartido", imperante en gran parte de las monarquías europeas del Antiguo Régimen ${ }^{15}$.

El monarca se presentaba en su discurso legitimador como el titular único y privativo de la soberanía, entendida ésta en el sentido bodiniano ${ }^{16}$. Ahora bien, con el profesor J. Pierre Dedieu, habría que recordar que el poder de los reyes absolutos conocía en la práctica importantes limitaciones que "no eran sólo de hecho, sino también de derecho, que no eran imperfecciones, sino parte del ser de la monarquía", y que "formaban una verdadera constitución del reino"17. En el caso concreto de la monarquía española, se advierte que junto con el poder real coexistían otros poderes intermedios que en la segunda mitad del siglo XVIII contaban con una considerable capacidad de control e influencia sobre miles de personas. Entre ellos nos interesa mencionar aquí a la aristocracia, poseedora de amplios dominios señoriales, y a la Iglesia, que sumaba a la anterior circunstancia el control sobre las conciencias de los hombres y mujeres de la época.

En los primeros años del reinado de Carlos IV se constata el predominio de las buenas relaciones entre la Corona y la Casa del Infantado. Así lo pone de manifiesto la decidida y activa participación del duque en la Guerra contra la

14. ELIAS, Norbert, La sociedad cortesana, Madrid, F.C.E., 1993 (1ª ed. 1969), pp. 12 y 34. En las limitaciones del poder absoluto también haría énfasis el profesor Geshard OESTREICH: Neostoicism and the early modern state, Cambridge, Cambridge University Press, 1982, esp. pp. 258-262.

15. BERNARDO ARES, José Manuel de, «Rey y reino: el binomio estatal de la Corona de Castilla en el siglo XVII", en CASTELLANO, Juan Luis, et alii (Eds.), La pluma, la mitra y la espada: estudios de historia institucional en la Edad Moderna, Madrid, Marcial Pons, 2000, p. 350. Esta definición se encuentra ya explícita en la obra de G. OESTREICH, para quien "Absolute monarchy is characterized by its tendency to exclude other forces from participation in national government at home and in relation to other countries". Véase: op. cit, p. 259. En las últimas décadas el concepto de absolutismo ha sido sometido a un nuevo examen, véase: ASCH, R. G. (ed. lit.) y DUCHARDT, H. (coord.), El absolutismo, ¿un mito? Revisión de un concepto historiográfico clave, Barcelona, Idea Books, 2000.

16. Ph. Sueur recordaba que en el discurso de poder monárquico, la voz « absolu » significaba esencialmente «libre», «indépendant de toute puissance politique extérieure et qu'il ne partage pas son autorité souveraine à l'intérieur», cfr. Histoire du droit public français, XVe-XVIII siècle : la genèse de l'État Contemporain, vol. I, Paris, Presses Universitaires de France, 1989, pp. 123 y 138. Sobre la vertebración y formas de legitimación del discurso de poder absolutista, véase: COSANDEY, Fanny, L'absolutisme en France: histoire et historiographie, Paris, Éditions du Seuil, 2002.

17. DEDIEU, Jean Pierre, "Dinastía y élites de poder en el reinado de Felipe V", en FERNÁNDEZ ALBALADEJO, Pablo (Ed.), Los Borbones, dinastía y memoria de nación en la España del siglo XVIII, Madrid, Marcial Pons, 2002, p. 383. Ver también: GUILLAMÓN ÁLVAREZ, F. Javier, Reformismo en los límites del orden estamental (estudios de historia moderna de España: de Saavedra Fajardo a Floridablanca), Murcia, 2010, pp. 353-412. 
Convención Francesa, que le valdría el nombramiento de gentilhombre de cámara con ejercicio ${ }^{18}$. Sin embargo, el malestar de la aristocracia en general, que se había dejado sentir ya en los reinados anteriores, continuaba latente. Buen ejemplo de ello es el escrito del conde de Teba, futuro conde del Montijo, perteneciente al partido del conde de Aranda y posteriormente vinculado al partido fernandino. El título de su Discurso sobre la autoridad de los Ricos hombres sobre el Rey y cómo la fueron perdiendo hasta llegar al punto de opresión en que se halla hoy (1794) revela bien a las claras el objeto de la denuncia de su autor.

En el caso concreto que nos ocupa, la línea divisoria que marcaría el surgimiento de las graves tensiones entre la Casa del Infantado y el poder real se situaría entre 1796 y $1798^{19}$. Manuel Godoy anotó en sus Memorias que en la primera fecha se escuchó por vez primera la voz crítica del duque del Infantado, disconforme con la alianza que la monarquía española acababa de concertar con la república revolucionaria francesa, cuya sola existencia era vista como una amenaza potencial para la estabilidad y seguridad de los tronos europeos. En particular, el de la Paz se refiere a la divulgación de un papel anónimo titulado Con todo el mundo guerra y paz con Inglaterra en el que se arremetía contra su persona. La autoría de este documento, que se hizo llegar a manos del propio Carlos IV, la atribuye sin titubeos a nuestro personaje ${ }^{20}$.

Por su parte, 1798 fue el año en que se pusieron en marcha las medidas reformistas de Miguel Cayetano Soler, cuya aplicación afectaba negativamente a los intereses de buena parte de los grupos privilegiados, como veremos más adelante. Las disensiones se aplacarían parcialmente en 1801, año de la guerra de España contra Portugal, para rebrotar a su término con inusitada virulencia.

$\mathrm{Al} \mathrm{empeoramiento} \mathrm{de} \mathrm{las} \mathrm{relaciones} \mathrm{entre} \mathrm{la} \mathrm{Casa} \mathrm{señorial} \mathrm{del} \mathrm{Infantado} \mathrm{y}$ la Corona en el marco de la última década del siglo XVIII no fue ajeno el renovado impulso que recibieron las políticas de incorporación al patrimonio real de oficios municipales y de lugares de señorío, actuación no exenta de contradicciones y que obedeció a las apremiantes necesidades del erario regio ${ }^{21}$.

18. El borrador de la carta que el duque del Infantado eleva a Carlos IV proponiendo la formación de un regimiento de infantería aparece con fecha de 3 de abril de 1793. SNAHN, Osuna, ct. (cartas) 201, doc. 38. El nombramiento de Infantado como gentilhombre de cámara de don Pedro Alcántara de Toledo y Salm-Salm tuvo lugar el de 13 de mayo de 1794, según decreto de 4 de abril del mismo año. Archivo General de Palacio, (AGP), Reinado Carlos IV, Cámara, leg. 2 (1).

19. DEMERSON, Paula de, "El escrito del conde de Teba: el "Discurso sobre la autoridad de los ricos hombres", en Hispania, $\mathrm{n}^{\circ} 31$ (1971), pp. 137-156.

20. GODOY, Manuel, Memorias, LA PARRA, Emilio y LARRIBA, Elisabel, (Eds.), Alicante, Universidad de Alicante, 2008, p. 365.

21. Numerosos autores han venido insistiendo en las limitaciones de la política de reincorporación de señoríos auspiciada por Carlos IV. Quizá uno de los casos más llamativos 
Carlos IV no había mostrado reparo alguno en diciembre de 1792 en extender a favor de Infantado la confirmación del título de alguacil mayor de millones de la ciudad de Guadalajara, como tampoco lo tuvo dos años después al reconocerle el de alférez mayor de la misma ciudad ${ }^{22}$. Sin embargo, la pacífica posesión de los cargos de esta naturaleza, fuente de honorabilidad y, por ende, de prestigio social para la aristocracia, se vio interrumpida por las reales órdenes de 24 de junio de 1797 y 5 de septiembre de 1798, que detallaban el modo de proceder a las incorporaciones de los que el discurso real definió como "los oficios enajenados a la Corona".

Si bien la fuerte presión ejercida por los grupos privilegiados no tardaría en dar sus frutos -el sobreseimiento de la última disposición citada era decretado el 6 de noviembre de 1799-, muchos de los poseedores de oficios se vieron obligados a presentar ante el gobernador del Consejo de Hacienda, a la sazón Josef Godoy, los "títulos de pertenencia y ejercicio para que de plano y sin figura de juicio los examinase y me propusiese los que tuviere por legítimos a fin de despacharles el de confirmación, entregando en las Caxas de reducción de Vales el importe de la tercera parte en que se estimen (...)"23. En 1801 Infantado, en calidad de afectado, tuvo que depositar 8.000 reales de vellón en la Caja de Reducción de Vales Reales para obtener el reconocimiento de la posesión a "su Casa, Estados y mayorazgos" de los oficios de alférez mayor, alcalde

sea el de Manuel Godoy. Paralelamente a sus ascensos políticos, y en la mayoría de las veces por concesión real, Godoy, como miembro de la aristocracia de nueva creación, incorporó a su patrimonio particular amplias extensiones territoriales en calidad de señoríos en reconocimiento a sus servicios y fidelidad al rey. Así, en 1798, mediante permuta de bienes con Carlos IV, consiguió el señorío de la Albufera de Valencia; en 1803 compró el Estado de Sueca a la Corona y fundaba dos mayorazgos: el ducado de Alcudia y el ducado de Sueca. LA PARRA LÓPEZ, Emilio, Manuel Godoy...pp. 254-259. Para una mayor profundización en el estudio de la política regalista de la Corona, consultar también: GARCÍA MONERRIS, Carmen, La Corona contra la Historia. José Canga Argüelles y la reforma del Real Patrimonio valenciano, Valencia, Universitat de València, 2005, pp. 44-55.

22. Confirmación del título de alguacil mayor de millones de la ciudad de Guadalajara en favor de Pedro Alcántara de Toledo Salm-Salm por fallecimiento del duque del Infantado, de 12 de diciembre de 1792, en SNAHN, Osuna, leg. 1877, doc. 9 (1-2). Confirmación del título de alférez mayor de la ciudad de Guadalajara en favor de Pedro Alcántara de Toledo y Salm-Salm por fallecimiento del XII duque del Infantado, de 18 de enero de 1794, Aranjuez. SNAHN, Osuna, leg. 1877, doc. 10.

23. Real cédula de SM y señores del Consejo por la cual se manda guardar y cumplir el decreto inserto en que se dispone que el Consejo de Hacienda sobresea por ahora en la ejecución de las órdenes expedidas sobre la incorporación a la Corona de aquellos oficios enajenados. Y que los dueños de ellos presenten los títulos de su pertenencia y sirvan con tercera parte de su valor para las cajas de reducción de vales, Imprenta Real, 1799, en SNAHN, Osuna, c. 3907 , doc. 78 . 
mayor y escribano de padrones de la ciudad de Guadalajara ${ }^{24}$. Las elevadas contrapartidas económicas exigidas a la aristocracia por el mantenimiento de unos cargos que consideraban legítima propiedad no hicieron sino acusar su descontento con el gobierno.

Por último, hay que mencionar que en 1804 se reabrió en el Supremo Consejo de Hacienda el inacabable pleito de incorporación al patrimonio real de la baronía de Alberique, en poder de la Casa del Infantado desde siglos atrás, una circunstancia que, al parecer, Miguel Cayetano Soler se empeñó personalmente en propiciar, o al menos esta era la opinión más extendida en los círculos en los que Infantado se movía por entonces ${ }^{25}$. En uno de los documentos que hizo públicos, el duque llegó a confesar "la repugnancia" que le merecía "el sistema de nulidad a que quieren reducirse las enajenaciones hechas por los señores reyes en uso de su legítima potestad real (...)", a la vez que abría el siguiente interrogante: "¿se querrá por ventura, a pretexto de la incorporación, arrancar del poder de los dueños todos aquellos pueblos y territorios que se les concedieron por unas causas tan justas, tan calificadas y de tan urgente necesidad y utilidad del Reyno y del Estado?"26. Este pleito acabaría por provocar una nueva y profunda brecha en las relaciones de la Casa del Infantado con la Corona, por considerarlo la primera un ataque contra la integridad de sus Estados y, por extensión, al poder señorial.

El duque llegaría a escribir que finalizado el fugaz conflicto contra Portugal (1801), "se retiró a su casa, abstraído de todo asunto militar y político, empleándose en otros de utilidad al Estado", como el fomento de la industria y el comercio ${ }^{27}$. Pero lo cierto es que no tardó mucho en entregarse a la conspiración contra Godoy y la política de reformas económicas y militares de la que

24. Cédula de Carlos IV que certifica la entrega de 8.000 reales de vellón por el duque del Infantado para el reconocimiento de los oficios de alférez mayor, alcalde mayor y escribano de padrones de la ciudad de Guadalajara, de 23 de diciembre de 1801, y cédula de confirmación de los mencionados oficios en favor del duque del Infantado, de 19 de enero de 1802. SNAHN, Osuna, leg. 1876, doc. 10.

25. Un importante testimonio a este respecto es el que ofrece lady HOLLAND, quien asistió con asiduidad a las tertulias del duque del Infantado durante estos años, como escribe en su conocido diario: The Spanish Journal of Elisabeth Lady Holland (1791-1811), Earl of Ilchester, London, 1910, esp. pp. 157-158.

26. TOLEDO Y SALM-SALM, Pedro Alcántara de, Por el duque del Infantado en el pleyto con los señores fiscales y la villa de Alberique, sobre la incorporación de dicha villa a la Real Corona, Imprenta de la viuda de don Joaquín Ibarra, Madrid, 1804, p. 16v y 40 r, en SNAHN, Osuna, leg. 1930, doc. 5.

27. TOLEDO Y SALM-SALM, Pedro Alcántara de (duque del Infantado), Manifiesto del duque del Infantado en enero de 1821, Oficina de Francisco Martínez Dávila, Madrid, 1821?, pp. 12, en BNE, R/61722. 
se convirtió en símbolo. En este sentido, resultan clarificadores los comentarios del propio Godoy, quien en su exilio afirmó que Infantado fue "el primer campeón que desde un principio se movió en contra mía"28.

\section{Infantado, miembro del partido fernandino}

\section{El primer destierro (1804-1806)}

"Tanto como es difícil en los gobiernos absolutos levantarse un partido poderoso y enemigo sin tener quien lo sostenga en las regiones altas de la corte, tan fácil le es formarse si se recluta bajo nombres y banderas que prometan la impunidad y ofrezcan visos de un buen éxito"29.

El intento de Carlos IV y Godoy de ampliar el ámbito jurisdiccional de la Corona, si bien no atentaba contra la posición social de las élites tradicionales, sí menoscababa sus intereses. Esta circunstancia motivó su oposición, que se canalizó en parte a través de las facciones activas en el seno de la corte, el ámbito por excelencia de la política del Antiguo Régimen ${ }^{30}$.

A partir del estudio de la correspondencia entre Godoy y María Luisa de Parma fechada hacia 1804, Carlos Seco Serrano advertía la existencia de intrigas en las estancias de los príncipes de Asturias orientadas a minar la política interior y exterior de Carlos IV ${ }^{31}$. Llama la atención el considerable número de aristócratas que aparecieron estrechamente vinculados a esta facción. Además de Infantado y San Carlos, quienes junto con Escoiquiz, el antiguo preceptor del príncipe de Asturias, figuraron como su cabeza rectora, destacan los nombres del duque de Montemar, del marqués de Castelar, de Ayerbe, Valmediano, del conde de Teba -después del Montijo-, del de Orgaz, Villariezo, Bornos, Altamira y los hermanos Palafox ${ }^{32}$.

La gestación del partido del príncipe de Asturias (también llamado partido inglés, por la decidida defensa que hizo al menos hasta 1806 de la alianza con la "moderada" monarquía inglesa), coincide en el tiempo con la aparición de importantes tensiones políticas y sociales, de las cuales constituyen buen ejemplo algunas de las medidas dictadas por Carlos IV. Entre 1804 y 1805 acabaron siendo desterrados de la corte y sitios reales decenas de miembros de la alta

28. GODOY, Manuel, Memorias., p. 365.

29. Ibid., p. 876.

30. Cfr., MARTíneZ Millán, José, "La Corte de la monarquía hispánica", Studia Historica. Historia Moderna, no 28 (2006), p. 57.

31. SECO SERRANO, Carlos, Godoy, el hombre y el político, Madrid, Espasa-Calpe, 1978, pp. 163, 167-183. LA PARRA, Emilio, "De la disputa cortesana a la crisis de la monarquía...", p. 257.

32. LA PARRA, Emilio, "Los hombres de Fernando VII...", p. 139. 
nobleza por razones políticas ${ }^{33}$. Concretamente en 1804 se prohibía tanto la circulación de pasquines y otros "papeles sediciosos e injuriosos a personas públicas y particulares", así como la posesión de imprentas a las "comunidades ni personas privilegiadas", a excepción de los seculares sujetos a la jurisdicción $\mathrm{real}^{34}$. En junio de ese mismo año, lady Holland, asidua asistente a las tertulias celebradas en la casa del duque, y por entonces residente en España, escribía en su diario:

"The rumours of the King's illness and bad state of health, the uncommon number of troops brought into Madrid (not less than 14.000) daily slights put on the P. [prince] and Princess of Asturias, excite suspicions of some designs being in agitation" 35 .

El estado actual de la investigación nos permite afirmar, por tanto, que el XIII duque del Infantado hizo su entrada en el terreno de la política del Antiguo Régimen por la senda de la conspiración en calidad de miembro del partido fernandino, algo que no pasó desapercibido a sus contemporáneos. El del III Baron Holland, miembro del partido Whig (1773-1840), llegaría a escribir sobre nuestro personaje:

"His pursuits were rational and manly, he had some ambition, and till called upon to take an active part in affairs, was thought to possess great capacity for them, combined with principles that would direct it to the benefit of his country. Perhaps it was unfortunate for the formation of his political character, that he was initiated in business of important by a confidential intercourse with Ferdinand [prince of Asturias]"36.

Parece que las críticas que Infantado lanzara contra la política interior y exterior de la Corona, unido a su papel de mediador oficioso entre los príncipes de Asturias y la corte de Nápoles, fueron las razones que motivaron la expedición de la disposición real de carácter reservado que lo confinaba fuera de la corte y sitios reales a finales de $1804^{37}$. Distintas evidencias documentales

33. Entre los aristócratas afectados por la oleada de destierros, aparte del propio Infantado, destacaron la condesa del Montijo, el conde de Miranda, el marqués de Villafranca, el conde de Oñate y la duquesa de Veragua. Véase: LA PARRA LÓPEZ, Emilio, Manuel Godoy..., p. 355. El profesor Morange apunta a que la expulsión de la corte y sitios reales del duque del Infantado en 1804 se sitúa en el marco de la segunda oleada de destierros mandada por Godoy. Véase: Paleografía (1779-1819) del "Pobrecito holgazán", Sebastián Miñano y Bedoya, Salamanca, Universidad de Salamanca, 2002, pp. 142 y 160. Del mismo autor, consúltese: Siete calas en la crisis del Antiguo Régimen español, Alicante, Instituto de Cultura Juan Gil-Albert, 1990, p. 298.

34. Ver Novísima Recopilación de las Leyes de España (1805), Libro 8, Título XV, ley V.

35. HOLLAND, Lady, The Spanish Journal..., p. 151.

36. FOX, Henry Richard (3rd baron Holland), Foreign reminiscences by Henry Richard lord Holland, edited by his son Henry Edward lord Holland, London, 1850, pp. 110-111.

37. No olvidemos que Nápoles era uno de los reinos potencialmente amenazados por la expansión napoleónica, extremo que corroboró la caída de la dinastía Borbón en 1806 
inducen a concluir que, en efecto, la real orden de destierro fue dictada por estas fechas. Al discurrir por el ramo de la guerra, al expediente militar del duque acabaron por adjuntarse varias representaciones y oficios que así lo confirmarían. En uno de esos escritos, fechado en 12 de julio de 1805, se refiere "la multitud de sinsabores que desde fines del año próximo pasado ha experimentado y experimenta el duque" a consecuencia de la "premura con que se le mandó salir de Madrid"38. Especial atención merece la súplica manuscrita que Infantado se atrevió a elevar a la reina desde Guadalajara el 2 de febrero de 1805, en la que se lamentaba en los siguientes términos:

"Quién podrá mejor que VM si gusta, borrar del ánimo del rey las impresiones con que alguna calumnia pudo haber desconceptuado? (...) El talento y magnanimidad de VM sabrán representar en su corazón [se refiere al del rey] aún más vivamente que yo pudiera hacerlo por escrito, el sentimiento que acompaña forzosamente a quien sufre un golpe como el que yo experimento (...) no deje [VM] de poner todos los medios posibles hasta conseguir por su gracia volverme a la de mi rey"39.

Algo más de dos décadas después de los sucesos a los que nos referimos, el propio Infantado confesaba en una representación elevada a Fernando VII que su primera expulsión de la corte se debió al descubrimiento de las conversaciones con Carlos Caracciolo, duque de Santo Teodoro, entonces embajador de Nápoles en España, quien le había aconsejado defender a los príncipes de Asturias

y la proclamación como rey de José Bonaparte. A los contactos del duque del Infantado con personalidades políticas napolitanas aludieron numerosos testimonios. Savary, por ejemplo, llegaría a escribir: "Il n'est pas indiférent que l'on sache ici qu'en faisant la visite du cabinet du duc de l'Infantado l'on trouva la correspondance de la reine de Naples et du prince Royal de ce Pays, avec le prince des Asturies, qui, comme l'on sait, avait épousé une fille de la reine de Naples. La plupart de ces lettres avaient été écrites dans le temps que les Français s'emparaient du royaume de Naples, à la suite de l'ouverture du port aux troupes russes et anglaises [...] ».ROVIGO, duc de (Savary), Mémoires du duc de Rovigo pour servir à l'Histoire de l'empereur Napoléon, t. IV, A. Bossange, París, 1828, pp. 19-20.Ver también: GODOY, Manuel, Memorias, pp. 365 y ss. KOSTKA BAYO, Estanislao de (?), Historia de la vida y reinado de Fernando VII de España, tomo I, Imprenta de Repullés, Madrid, 1842, p. 19. VADILLO, José Manuel, Apuntes sobre los principales sucesos que han influido en el actual estado de la América del Sud, París, Imprenta de Demonville, 1830, p. 24.

38. "Oficio adjuntado al memorial del duque del Infantado al rey, solicitando permiso para trasladarse a Torrelavega", en el expediente militar de Infantado, AMS, Personajes célebres..., pp. $6 \mathrm{v}$ y $10 \mathrm{v}$.

39. Una nota marginal indica que el memorial fue visto el 31 de mayo de 1805. Muestra de las malas relaciones entre Infantado y el de la Paz es el recurso de Infantado a la reina y no a Godoy, a quien era común en estos casos, para suplicar clemencia al soberano. AMS, Ibídem, p. 4r. 
frente a la animosidad de Godoy ${ }^{40}$. Pero fue en su Manifiesto de 1821 donde Infantado arrojó toda sombra de duda sobre los móviles que motivaron su actitud claramente hostil hacia el de la Paz a la altura de 1804:

"La ilimitada ambición de don Manuel Godoy, la desconcertada política con que iba minando todas las bases del Estado, preparando la ruina de éste y de la Nación toda, chocaban demasiado con mis principios patrióticos y los de mi fidelidad para que yo doblase la cerviz ni dejase de desaprobar abiertamente sus operaciones. Fui desterrado por la arbitrariedad que entonces regía (...) a la Alcarria"4l.

Los escritos enviados a los reyes entre 1805 y 1806 solían concluir con similares palabras: "recordando con este motivo mi respetuosa voluntad, aguardo con resignación sus soberanos preceptos en punto a mi destierro (...)" ${ }^{42}$. Tales preceptos le fueron comunicados por fin el 1 de abril de 1806 .

\section{La conspiración de El Escorial (octubre de 1807)}

En el contexto de crisis política y malestar social de 1806-1807, el partido fernandino, y a su cabeza el príncipe de Asturias, comenzó a urdir una trama conspirativa orientada a derribar a Godoy, que fue acompañada de una campaña denigratoria de la persona de los reyes y de la de su "hombre de confianza" 43. Godoy, en el borrador de una carta con fecha de 3 de noviembre de 1807, muy probablemente dirigida a Eugenio Izquierdo, tras mencionar el "ensayo del tratado de Portugal" y las dificultades que ofrecía "la conquista" de los portugueses, anotaba:

"Ahora la novedad grande es la del arresto del Príncipe de Asturias. Escoiquiz era el autor de un plan para deponer el gobierno actual. (...) Infantado, Orgaz, Ayerbe y otros criados del cuarto, los cómplices, sabiendo todo por el embajador Beauharnais. Madrid está medio movido (...) el embajador ha dicho pondrán

40. De esta representación, con fecha de 18 de agosto de 1826, encontramos una copia traducida al francés, en : Archives des Affaires Étrangères (AAE), (La Courneuve, Paris), Correspondance politique. Espagne, vol. 737(1826, juillet-septembre), doc 89.

41. TOLEDO Y SALM-SALM, Pedro Alcántara (duque del Infantado), Manifiesto del duque del Infantado en enero de $1821 \ldots$, p. 11.

42. Infantado elevaba esta representación al rey a través de Pedro Cevallos, Secretario de Estado e Interino del Departamento de Guerra, el 31 de octubre de 1805, Guadalajara. AMS, Ibídem, p. 9r.

43. El profesor Emilio La Parra escribe que entre los receptores de los papeles difamatorios que el príncipe de Asturias mandó escribir y distribuir figuraban los nombres de aristócratas como los marqueses de Miraflores y de Belebeite, los duques de Sotomayor, Cerbellón, Medina de Rioseco y la Yarsa, las duquesas de Alba, de los Llanos y de Lerma. Véase: Manuel Godoy..., pp.337 y 340. 
en Madrid su cuartel general las tropas francesas. Estoy en el sitio. Todo mi cuidado es poco para tantos enemigos. Pero el cañón los reducirá (...)"44.

El 28 de octubre de 1807 Carlos IV había entregado al marqués de Caballero, Secretario del Despacho Universal de Gracia y Justicia, varios papeles encontrados en poder del príncipe de Asturias que atestiguaban la preparación de una trama política dirigida supuestamente contra su persona, circunstancia que coincidía prácticamente en el tiempo con la firma del Tratado de Fontainebleau (27 de octubre de 1807). En su real decreto de 30 de octubre, el monarca declaraba públicamente que su sucesor "había admitido un plan para destronarme" siguiendo "las instrucciones que recibía de los malvados" 45 .

Las declaraciones del propio príncipe de Asturias motivaron que el aristócrata resultara, junto con el arcediano de Alcaraz, Juan de Escoiquiz, el prin-

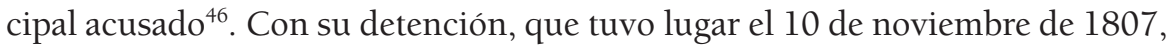
se cumplía la real orden de arresto de 31 del mes anterior. Ahora bien, hay que subrayar que en la nómina de implicados en la causa de El Escorial salieron a relucir los nombres de otros destacados aristócratas, a saber: los del duque de San Carlos, el marqués de Ayerbe, el conde de Bornos y el de Orgaz, un dato éste que habría que poner de nuevo en relación con el descontento que albergaba una parte muy importante de la aristocracia con respecto a la orientación política que Carlos IV estaba imprimiendo a la monarquía.

Los miembros del grupo cortesano del que formó parte el duque del Infantado no reconocieron su oposición al reforzamiento del poder del soberano absoluto. Antes bien, este móvil quedó oscurecido por otro de sus principales objetivos: acabar con la progresiva concentración de poderes políticos y militares en la persona de Godoy y extralimitación a la hora de ejercerlos.

Preso en la celda rectoral de San Lorenzo, Infantado prestó declaración por primera vez el 15 de noviembre de 1807 ante el juez comisionado, Domingo Fernández Campomanes. El principal cargo que Simón de Viegas, el fiscal más antiguo del Consejo, imputó al aristócrata fue el de intentar perpetrar el delito de lesa majestad contra Carlos IV, el crimen más grave que podía cometerse en el Antiguo Régimen: comportaba para el reo la pena capital, la confiscación de

44. AGP, Familia Godoy, c. 22948, exp. 8.

45. Real decreto de 31 de octubre de 1807, en Expediente formado en virtud del Real Decreto de SM participando al Consejo las resoluciones que se había servido tomar con motivo del Plan que se trazaba en su palacio contra su Real Persona, AHN, Consejos, 5525, exp. 1.

46. En el Archivo Histórico Nacional se encuentra parte del expediente del arresto del duque del Infantado Expediente relativo al arresto del teniente general duque del Infantado, en Papeles relativos a los sucesos de El Escorial, Aranjuez y venida del Exército Imperial, para unirlos a los que se vayan hallando en las papeleras de los oficiales, secretaría de la presidencia y cámara de Castilla, AHN, Consejos, leg. 50.218, exp. sn. 
todos los bienes y el desdoro de su persona y de la de toda su Casa ${ }^{47}$. Infantado negó esta acusación y alegó a su favor que su participación en la trama se redujo a apoyar la adopción de una serie de medidas preventivas orientadas a defender el legítimo orden sucesorio. Y es que, según noticias que "estaban en la voz pública", los partidarios de Godoy "andaban haciendo gente, ya con descaro, esparciendo proposiciones de que la familia Borbón había degenerado", y que era necesaria sustituirla por una nueva dinastía: la que encarnaría Godoy ${ }^{48}$.

En los interrogatorios de los inculpados de El Escorial salió a la luz la autoría de un decreto en que Fernando, en calidad de rey, otorgaba provisionalmente a Infantado "el mando supremo militar [...] en toda la extensión de Castilla la Nueva, inclusos Madrid y sitios reales", con todas las facultades políticas y militares que concentraba Manuel Godoy. El contenido de esta disposición, cuyo original nunca sería hallado, fue conocido gracias a Escoiquiz, quien se avino a reescribirlo en uno de los interrogatorios a los que fue sometido, siendo adjuntado al expediente de la causa el 14 de noviembre de 1807. Al leerlo, Infantado "dijo que enterado de él, lo halla correspondiente al firmado por SA, aunque no puede asegurar sean las precisas palabras en que fue concebido el decreto por que se le ha preguntado", y, nota importante reconoció que en las atribuciones que se le conferían "le parece estaban comprendidas las [facultades] del SS. Príncipe Generalísimo Almirante"49.

Refiriéndose a los años de 1806 y 1807, nos dice Norvins que "la casa de la duquesa viuda del Infantado [en Madrid], cuyo hijo era amigo y consejero del príncipe, era el punto donde se reunían los descontentos", y que "el susodicho M. de Beauharnais [embajador de Francia en España] concurría con asiduidad a las tertulias de Infantado desde algún tiempo" 50 . Para consumar sus objetivos, a finales de 1806 la facción del príncipe de Asturias, tradicionalmente partidaria de estrechar los lazos con Inglaterra, decidió invertir sus oficiosas "alianzas internacionales". Los principales acusados en la causa de El Escorial reconocieron en sus declaraciones judiciales que por estas fechas iniciaron conversaciones con destacadas personalidades políticas francesas con el fin de lograr

47. AGP, Papeles reservados de Fernando VII, t. II, p. 119.

48. El recurso a las expresiones de "voz pública" u "opinión pública" por parte de los inculpados es una constante en sus declaraciones y se utiliza significativamente como argumento justificatorio de la trama conspirativa contra Godoy. Sus afirmaciones, lógicamente tendenciosas y autoexculpatorias, apuntan a que la mayoría del pueblo rechazaba el encumbramiento de Godoy.

49. Encontramos la declaración judicial del duque del Infantado en noviembre de 1807 en: AGP, Papeles Reservados..., p. 311v y ss.

50. NORVINS, M. de, Historia de Napoleón, tomo III, $1^{\text {a }}$ parte, Durey Librero Editor, París, 1829, p. 42. 
el apoyo del emperador y asegurar así los derechos dinásticos del príncipe Fernando, amenazados por las supuestas pretensiones al trono del Generalí$\operatorname{simo}^{51}$. Ciertamente, ése pudo ser el momento más a propósito dadas las tensiones diplomáticas entre la corte española y el imperio francés. Y es que las tímidas resistencias que una monarquía cada vez debilitada opuso a las presiones del imperio francés, que exigía cada vez mayores esfuerzos económicos y militares, hicieron que Godoy acabara siendo visto por Francia como un personaje de dudosa confianza que no aseguraba plenamente la alianza con la monarquía española ${ }^{52}$.

Los conflictos habidos en el seno de la familia real española acabaron por confirmar a Francia la visión que de la monarquía se había forjado: la un reino decadente, débil desde el punto de vista político, y cuyos soberanos se hallaban desprestigiados ante una opinión pública contraria al despotismo de Godoy. En estas ideas insistían los informes que el embajador francés en la corte española enviaba a París. En noviembre de 1807, Beauharnais escribía:

«L'opinion publique dans cette occasion s'est fortement prononcé à Madrid, c'est la même dans toutes les provinces (...). Les discours (...) dans la capitale, ont pour objet de peindre sous les plus vives couleurs l'oppression sous laquelle gémissent tous les ordres de l'état, de laquelle ils ne pensent être délivrés que par la puissante protection de l'empereur» ${ }^{53}$.

El control político de Portugal y España, a los que estaban ligados importantes extensiones territoriales en América y Asia, y de capital importancia desde el punto de vista geoestratégico en el enfrentamiento contra Inglaterra, fue contemplado por Francia como un objetivo fácil de alcanzar. Aprovechando la cada vez mayor tensión reinante en la corte española, y una vez asegurada la paz con Rusia por el Tratado de Tilsit, Napoleón iría dando forma a su plan de ocupación de la Península Ibérica. En noviembre de 1807 las tropas francesas se encontraban ya a tan sólo treinta leguas de Madrid ${ }^{54}$.

51. El arcediano y antiguo preceptor del príncipe de Asturias confesó que fue Infantado quien lo condujo hasta el embajador francés cumpliendo instrucciones directas del príncipe de Asturias, unos manejos que el duque del Infantado reconocía en su declaración de 17 de noviembre de 1807. AGP, Papeles reservados de Fernando VII, tomo II, pp. 327 r, 390v. Las declaraciones del duque en: ibid., pp. 281r-v y 293-298v.

52. El profesor Emilio La Parra refiere la publicación el 6 de octubre de 1806 de un documento en el que Godoy había llamado a la población española a prepararse ante un posible conflicto armado, declaración ante la cual Francia no tardó en darse por aludida. LA PARRA, Emilio, " Méfiance entre les alliés »,... p. 20.

53. Archives Nationales de France (Paris), 251AP/4, Correspondance avec les ministres de M. François de Beauharnais ambassadeur de France en Espagne (1807).

54. Correspondencia entre Manuel Godoy y Eugenio Izquierdo en noviembre de 1807, en AGP, Familia Godoy, c. 22948, exp. 8. 
Infantado permaneció preso e incomunicado tres meses, al cabo de los cuales recibió una real orden de 27 de enero de 1808 que lo confinaba fuera de la corte. En este último documento, el rey prohibió que se le considerara individuo del ejército, advirtiendo que "si VE quebrantase el destino, se le imponga la pena de traidor" 55 . Esta vez, Infantado, por propia elección, fijó su residencia en Écija (Sevilla). Comenzaba así el que sería su segundo destierro, en el que se hallaba en el momento en que estallaba el motín de Aranjuez.

\section{El motín de Aranjuez y el ascenso al poder}

“(...) y el vulgo, que siempre atribuye a los ministros sus desgracias, reconcentraba todo su aborrecimiento en el Príncipe de la Paz, a quien creía omnipotente" ${ }^{56}$.

El motín de Aranjuez provocó que el príncipe de la Paz fuera exonerado de sus cargos por real decreto de 18 de marzo y forzó la abdicación de Carlos IV, que tuvo lugar al día siguiente. La forma en la que Fernando VII ascendía al poder carecía de precedentes históricos y se explica por la profunda crisis política en la que se hallaba sumida la monarquía. Con él llegaron al poder significados miembros del partido fernandino, defensor de un modelo de monarquía diametralmente opuesto al del absolutismo puro, el que propugnaran Carlos IV y Godoy, esto es, aquel "en que el monarca marcaba las pautas y su fiel servidor y amigo las ejecutaba, sin trabas institucionales de ninguna clase" ${ }^{157}$.

Para subir al trono, Fernando VII se valió de una insurrección que adquirió una importante dimensión popular que se extendió a Madrid y a distintos puntos de la geografía española. Hay que subrayar que en ella participaron directamente miembros de la aristocracia vinculados al partido fernandino. Es el caso del conde del Montijo, estrechamente vinculado al duque del Infantado, quien confesaba dos años más tarde que el general Solano, su mujer y Garay fueron "los únicos que supieron en Badajoz que mi ida en posta a Madrid a principios de marzo de 1808 era con ánimo determinado de derribar a Godoy a todo trance. Solano me guardó fielmente el secreto y me dio la palabra de honor de obrar siempre como buen español" ${ }^{58}$. Como Infantado, el conde se consi-

55. En la pieza novena de la causa de El Escorial encontramos la "sentencia y remisión de ella por el Gobernador interino del Consejo", de 25 de enero de 1808. AGP, Papeles reservados..., Ibid.

56. KOSTKA BAYO, Estanislao (?), Historia de la vida..., p. 21.

57. LA PARRA, Emilio, "De la disputa cortesana...", p. 259.

58. PALAFOX Y PORTOCARRERO, Eugenio de (conde del Montijo), Manifiesto de lo que no ha hecho el conde del Montijo, escrito para desengaño u (sic) confusión de los que de buena o mala fe le dicen autor de sediciones que no ha hecho ni podido hacer, Cádiz, Manuel Santiago de Quintana, 1810. BNE, R/60.385 (3). 
deraba autorizado para "librar la patria del monstruo que la devoraba con su avaricia y la vendía con su ambición, ignorancia y torpeza política".

El discurso inicial de poder de Fernando VII contemplaba los intereses de las élites sociales tradicionales del Antiguo Régimen, entre los que se encontraban los de la antigua aristocracia señorial. A este respecto, es sumamente significativo que el nuevo rey llamara a su presencia a destacados grandes de España y títulos para conferirles altos cargos del Estado, lo cual podría interpretarse a su vez como una muestra de los apoyos sociales con que contaba. Así, una de las primeras disposiciones de Fernando VII fue el nombramiento del duque del Infantado como coronel de Reales Guardias Españolas y presidente del Consejo de Castilla ${ }^{59}$. El autógrafo original del monarca, fechado en Aranjuez el 21 de marzo, rezaba así:

"Por la satisfacción que tengo de vuestra persona y celo con que me serviréis os he nombrado por presidente del Consejo, y tomaréis la posesión mañana; y espero cumpliréis con las obligaciones del oficio, de manera que descargaréis mi conciencia y la vuestra" ${ }^{60}$.

Infantado tomó posesión de la presidencia del primer tribunal supremo del reino el 24 de marzo en Madrid, el mismo día elegido por Fernando VII para hacer su entrada en la ciudad. El aristócrata asumió cometidos políticos de importancia, como el mantenimiento del orden público -muy alterado en Madrid tras los sucesos de Aranjuez- o el expediente de confiscación de los bienes de Manuel Godoy ${ }^{61}$.

Los variopintos ideales políticos del partido fernandino y su idea de la monarquía pueden inferirse a partir de algunas de las medidas que el nuevo rey dictó en el corto margen de tiempo del que se dispuso desde la subida al poder de Fernando VII hasta el momento en que cruzó la frontera española para entrevistarse con el emperador y legitimarse en el poder. La subida del joven rey al trono se presentó públicamente como el fin del despotismo ministerial, considerado como la causa última de la decadencia de la monarquía. De ahí el cuidado que se puso en evitar la concentración de excesivas atribuciones en un único individuo. Parece que el modelo a defender era el de una "monarquía

59. Ver el expediente: Causas, origen y progreso de los alborotos de Madrid de los días 19, 20, 21 y 22 de marzo de 1808 y primeras providencias adoptadas por el Consejo de Castilla (...), Archivo Histórico Nacional (AHN), Consejos, 5512, exp. 2.

60. Autógrafo de Fernando VII nombrando al duque del Infantado presidente de Castilla y Coronel de Reales Guardias Españolas en: SNAHN, Osuna, leg. 1984, 34 (1).

61. Secuestro de los bienes de Manuel Godoy, AHN, Consejos, 17806 ; causas, origen y progreso de los alborotos de Madrid de los días 19, 20, 21 y 22 de marzo de 1808 y las primeras providencias adoptadas por el Consejo de Castilla para contener a la gente y evitar desórdenes, AHN, Consejos, 5512, exp. 12. 
moderada" -el mismo que había sido defendido por la aristocracia española, pero también por la francesa, a lo largo del siglo XVIII ${ }^{62}$ - en la que el rey, cuya titularidad de la soberanía absoluta no llegaba a cuestionarse, debía encontrarse asistido en todo momento por los organismos consultivos tradicionales y por el consejo privado, en los que la aristocracia habría de tener una presencia sobresaliente.

En marzo de 1808, Fernando VII se presentaba públicamente no tanto como reformador, sino como restaurador de las leyes fundamentales que daban cuerpo a la constitución histórica de la monarquía española. Se trataba, en definitiva, de "regenerar restaurando". La designación del duque del Infantado como presidente del Consejo de Castilla y su integración en el consejo privado del rey simboliza la nueva alianza entre aristocracia y el rey, pero también evidencia la intención del monarca de otorgar un mayor protagonismo político a los órganos de poder polisinodiales: los consejos supremos. Las resultas de la entrada en el escenario de la monarquía española del Imperio francés nos impide hacer conjeturas acerca de las posibilidades de éxito que hubiera tenido esa nueva tendencia política.

Las primeras disposiciones de Fernando VII, que el Consejo de Castilla se encargó de circular por toda la monarquía, se orientaron a reforzar la asociación entre el joven monarca y la idea de "prosperidad" y "felicidad de sus pueblos". Esta imagen del soberano, que había comenzado a forjarse algunos años atrás y que ahora se proyectaba desde el poder, es la que perdurará en el imaginario popular en el contexto de la Guerra de la Independencia, y la misma de la que continuarían bebiendo pocos años después las nuevas élites de poder liberales ${ }^{63}$.

Fernando VII hizo escribir su particular versión del sentido y desenlace de la causa de El Escorial y la hizo publicar en la Gaceta de Madrid de 31 de marzo de 1808, para que "todos sus vasallos se instruyan en los procedimientos contra su Real Persona, varios criados suyos y otros sujetos que intervinieron en las ocurrencias de ella"64. De aquellos sucesos se hizo una lectura políticamente intencionada que presentó a Fernando VII como una víctima

62. CHAUSSINAND-NOGARET, Guy, La noblesse au XVIIIe siècle. De la Féodalité aux Lumières, Bruxelles, Editions Complexe, 1984, pp. 93-94.

63. El profesor Emilio la Parra apunta que "Como referente, podríamos partir de una fecha para precisar el nacimiento del mito de Fernando VII: el 5 de noviembre de1807". Ese día la Gazeta de Madrid publicaba el decreto por el que Carlos IV perdonaba a Fernando VII su implicación en la trama de El Escorial. LA PARRA, Emilio, "El mito del rey deseado", en DEMANGE et alii (eds.), Sombras de mayo, Madrid, 2007, p. 225.

64. Expediente formado en virtud del Real Decreto de SM participando al Consejo las resoluciones que se había servido tomar con motivo del Plan que se trazaba en su palacio contra su Real Persona, en AHN, Consejos, 5525, exp. 1. 
del despotismo de Godoy. En el citado número de la Gazeta, se puso especial cuidado en aclarar que:

"El haber recibido el decreto el duque del Infantado y el haber prestado a SM reinante algunas cantidades para gastos muy precisos, son los únicos delitos por que se ha procesado y acusado a un vasallo tan distinguido y benemérito".

La aureola de inocencia que envolvió al joven rey se proyectó también sobre sus consejeros íntimos, entre ellos Infantado, y los continuaría rodeando hasta el momento en que abandonaron el suelo español. A partir de entonces brillaría sólo en torno a Fernando VII.

\section{Conclusiones}

A la altura de 1804, y con el fin de contener el avance de las medidas reformistas y recuperar una parte de las parcelas de poder perdidas paralelamente al desarrollo del Estado absoluto, un nutrido grupo de aristócratas, entre los que destaca el XIII titular de la Casa del Infantado, pasó a formar parte del grupo de presión cortesana formado en torno a la persona que estaba llamada a convertirse en sucesor a la Corona: el príncipe de Asturias.

Las actuaciones del que en la época recibiera el apelativo de partido fernandino, se encaminaron a precipitar la llegada al trono de Fernando de Borbón. Si desde el punto de vista formal el cometido más importante del Generalísimo radicaba en "regenerar" la monarquía mediante la puesta en práctica de reformas, Infantado, a la altura de 1807, estaba dispuesto a asumirlo pero para todo lo contrario: suspenderlas y anularlas.

Las medidas reformistas impulsadas por Carlos IV y Godoy no sólo estuvieron motivadas por las necesidades apremiantes del erario real, sino también por el propósito de fortalecer el poder del monarca, objetivo que se sitúa dentro de la propia lógica de construcción del Estado moderno y que obedece a las nuevas circunstancias internacionales derivadas de la llegada al poder de Napoleón Bonaparte. He aquí una de las grandes contradicciones del sistema del Antiguo Régimen en su fase final: el denominado modelo de monarquía absoluta pura o plena, que exigía aumentar los ingresos fiscales, extender el ámbito de la jurisdicción regia, contar con un corpus burocrático amplio y eficaz en los distintos niveles de la administración regia y formar un ejército dependiente del rey y bien pertrechado, sólo podía llevarse a cabo en detrimento de una parte del poder social de las élites privilegiadas. Sin embargo, se daba la paradójica circunstancia de que estos grupos constituían, a su vez, uno de sus pilares fundamentales del régimen absoluto y de la sociedad estamental.

La penuria económica en la que se hallaba sumida la monarquía en las dos décadas finales del siglo XVIII, agravada por las malas cosechas, las continuas 
guerras y el recrudecimiento de la presión fiscal, hicieron que muchas medidas reformistas acabaran revestidas de gran impopularidad ${ }^{65}$. Esta circunstancia, unida a la cada vez mayor debilidad política de los gobiernos de Carlos IV, motivó que los grupos de oposición cortesanos, en los que significativamente figuraron destacados miembros de la aristocracia, ganaran cada vez mayor capacidad de maniobra y posibilidades de éxito, así como que calara socialmente su campaña denigratoria de Godoy, convertido en símbolo del despotismo.

Entre los apoyos que Fernando VII recibiera en marzo de 1808 adquirió un peso destacado la aristocracia. Ésta había depositado tempranamente en Fernando sus esperanzas de ver defendida su particular visión de la constitución histórica de la monarquía, lo que equivalía entre otras cosas a que la Corona respetara el poder social acumulado a lo largo de los siglos por las élites sociales tradicionales, devolviera su peso político y judicial a los organismos corporativos de la monarquía y suprimiera la novedosa figura del Generalísimo. Tras la llegada al trono de Fernando, y desde sus altos cargos políticos (la presidencia del Consejo de Castilla y su puesto en el consejo privado del monarca), Infantado se preparaba para participar en la restauración de la tradicional forma política de la monarquía española, intento abortado por la expansión territorial del Imperio Napoleónico, que puso sus miras en la Península Ibérica.

Las críticas que el partido fernandino había venido lanzando hacia lo que se vino en denominar despotismo o tiranía ministerial (esto es, la progresiva concentración de poder por delegación regia en manos de Godoy), acabaron desprestigiando socialmente al régimen absoluto. Tras la salida de Fernando VII de Madrid (abril de 1808), las abdicaciones de la dinastía Borbón en mayo de 1808 y las primeras reacciones hostiles de la población contra la ocupación militar francesa, a duras penas contenidas por las autoridades, el descrédito de Carlos IV y de la forma en la que había venido ejerciéndose el poder conoció una importante extensión social, arraigando sobre todo en las élites intelectuales y políticas. Así lo ponen de manifiesto los escritos publicados en los primeros meses de la guerra ${ }^{66}$. La dinámica bélica, unida al vacío de poder abierto tras las abdicaciones de Bayona, hicieron que una parte de los españoles acabara cuestionando los fundamentos mismos de la organización social tradicional y del poder absoluto, de lo cual constituye buena muestra el discurso del primer liberalismo español, un tema éste que habría que abordar en otro estudio.

65. HERR, Richard, España Contemporánea, Madrid, Marcial Pons, 2004, pp. 98-111.

66. Entre la extensa producción, podríamos destacar el Manifiesto imparcial y exacto de lo más importante ocurrido en Aranjuez, Madrid y Bayona desde el 17 de marzo hasta el 15 de mayo de 1808. Sobre la caída del Príncipe de la Paz y sobre el fin de la amistad y alianza de los franceses con los españoles, Madrid, 1808, BNE, R/60124 (14). 